\title{
DEVELOPMENT AND CHARACTERIZATION OF MUCOADHESIVE MICROSPHERE-LOADED INTRANASAL GEL OF VENLAFAXINE HYDROCHLORIDE
}

\author{
BHUPEN KALITA, KRITIKA SAIKIA*, BANASMITA KALITA
}

Department of Pharmaceutics, Girijananda Chowdhury Institute of Pharmaceutical Science, Assam, Guwahati, India. Email: kritsaikia5@gmail.com

Received: 24 May 2016, Revised and Accepted: 31 August 2016

\section{ABSTRACT}

Objective: The main objective of the present work is to develop and characterize a novel mucoadhesive intranasal microsphere gel formulation of drug venlafaxine to control the drug release through nasal mucosa and reach the target site with minimal side effect. The objectives of the study are (1) formulation of mucoadhesive microspheres, (2) evaluation of mucoadhesive microspheres, (3) formulation of mucoadhesive microsphereloaded nasal gel, (4) and evaluation of nasal gel.

Methods: Preparation of chitosan microsphere: The chitosan microspheres were prepared by emulsion cross-linking method. Preparation of microsphere-loaded gel: The nasal gels with varying concentrations of Carbopol 934P were prepared by dispersing required quantity of Carbopol in required quantity of distilled water with continuous stirring and kept overnight for complete hydration. The gel was then modified by the addition of varying proportion of hydroxypropyl methylcellulose (HPMC) K4M.

Results: The prepared microspheres were evaluated for size distribution, surface morphology by scanning electron microscopy, entrapment efficiency, compatibility by Fourier transform infrared spectroscopy, and differential scanning calorimetry. Entrapment efficiency of all formulations was found more than $70 \%$. Microsphere formulation containing drug and polymer in the ratio of 1:2.5 was found to be optimized. Optimized microsphere formulation was then incorporated in gel prepared using Carbopol 934P and HPMC. Prepared gel formulations were studied for viscosity, spreadability, and in-vitro drug release in simulated nasal conditions. Viscosity of the optimized batch of gel was recorded at 1056 centipoise. Drug release was prolonged for the microsphere-in-gel formulations compared to the microspheres alone. For the optimized batch of gel, cumulative drug release of $85.67 \%$ was found after $8 \mathrm{hrs}$.

Conclusion: The results suggest that venlafaxine hydrochloride mucoadhesive microsphere-loaded nasal gel would give sustained drug release and superior bioavailability in the brain sites.

Keywords: Venlafaxine, Chitosan, Mucoadhesive, Microsphere, Nasal gel.

(C) 2016 The Authors. Published by Innovare Academic Sciences Pvt Ltd. This is an open access article under the CC BY license (http://creativecommons. org/licenses/by/4. 0/) DOI: http://dx.doi.org/10.22159/ajpcr.2016.v9s3.13057

\section{INTRODUCTION}

Intranasal delivery has been recognized as a very promising route for the delivery of therapeutic compounds as well as biopharmaceuticals. The nasal route is especially advantageous as an alternative means for the deliveries of those drugs that undergo extensive first-pass metabolism or are sensitive to gastrointestinal decomposition. Intranasal delivery is quite a favorable way to circumvent the obstacles for blood-brain barrier (BBB), allowing the direct delivery of drug in the biophase of central nervous system (CNS) [1]. This is the only site in the human body where the nervous system is directly in contact with the surrounding environment. The nasal route, therefore, offers a potential for braintargeting drugs, providing further opportunities to enter the CNS and then act on CNS disorders. Intranasal delivery provides a non-invasive method by bypassing the BBB to rapidly deliver therapeutic agents to the brain, spinal cord, lymphatic, and to the vessel walls of the cerebovasculature for treating CNS disorders. Intranasal delivery also offers the advantage of simple administration, cost-effectiveness, and convenient [2].

Venlafaxine hydrochloride, an antidepressant, is used in the treatment of major depressive disorder, social anxiety disorder, generalized anxiety disorder, social anxiety disorder, and panic disorder [3]. This drug is extensively metabolized in the liver via CYP2D6 and thus has low oral bioavailability [4]. Therefore, intranasal delivery appears to be an attractive alternative. However due to low residence time of drug in nasal cavity it affects the absorption and in turn reduces the bioavailability of the drug [5]. Hence, the design of the nasal dosage forms has to be according to the anatomic and physiologic characteristics of nasal mucosa, and more particularly the mucociliary clearance (MCC) that limits the time available for drug absorption from the applied dosage form. Hence, the possible strategy to decrease rapid MCC is by using mucoadhesive formulations to prolong the residence time at the nasal absorption site and thereby facilitating the uptake of the drug [6].

Microsphere technology is one of the specialized systems becoming popular for designing nasal products, as it provides prolonged contact with the nasal mucosa and thus increases absorption and bioavailability. This is particularly appropriate to overcome certain limitations of the nasal route, i.e., rapid MCC that determines limited drug delivery through the nasal route, especially in the delivery of drugs with high molecular weight and hydrophilic properties. The particle size should be controlled and optimized in the range of 6-15 $\mu \mathrm{m}$ to minimize the deposition of the particles in the anterior part of the nasal cavity and also to the lungs. The solution to overcome the clearance is to formulate a gel which increases the contact time in the nasal mucosa [7]. The present work aimed to develop and characterize a novel mucoadhesive intranasal microsphere gel formulation of drug venlafaxine to control the drug release through nasal mucosa and reach the target site with minimal side effect.

\section{MATERIALS AND METHODS}

\section{Materials}

VENH was purchased from Merck Specialist Pvt. Ltd., chitosan was purchased from Spectro Chem. Pvt. Ltd., and glutaraldehyde, carbopol 934, and hydroxypropyl methylcellulose (HPMC) K4M were purchased from Himedia Pvt. Ltd. All other chemicals and reagents used in this study were of analytical grade. 


\section{Methods}

Drug-excipients compatibility study using Fourier transforminfrared spectroscopy (FT-IR)

The FT-IR studies were performed to study drug excipient interaction in the range of 4000-400 $\mathrm{cm}^{-1}$ using an FT-IR spectrometer (Bruker Model no-10059736), and data had been collected [8].

\section{Formulation of mucoadhesive chitosan microsphere}

The chitosan microspheres were prepared by emulsion cross-linking method. Chitosan solution $(2 \%, \mathrm{w} / \mathrm{v})$ was prepared in $4 \%$ aqueous glacial acetic acid by overnight stirring in a magnetic stirrer. The drug was dissolved in ethanol and mixed well in the polymer solution A volume of $6 \mathrm{ml}$ of the above resultant mixture was then injected through a syringe into $40 \mathrm{ml}$ of oil phase containing span $80(7 \% \mathrm{v} / \mathrm{v})$, and stirring was performed by mechanical stirrer at variable rpm to form water-in- oil emulsion. Oil phase was light-liquid paraffin. After 30 minutes of homogenization period, $1.0 \mathrm{ml}$ of glutaraldehyde $25 \%$ $(\mathrm{v} / \mathrm{v})$ was added to it slowly. It was then left for stabilization and crosslinking. Microspheres obtained were centrifuged at various rpm. The sediment was then washed with petroleum ether and acetone thrice, and then dried in a hot air oven at $50^{\circ} \mathrm{C}$ [9]. The composition of all the formulations is shown in Table 1.

\section{Evaluation of microspheres}

\section{Drug entrapment efficiency}

Powdered microspheres were suspended in $10 \mathrm{ml}$ of phosphate buffer (pH 6.4). After $24 \mathrm{hrs}$, the solution was filtered, the filtrate was centrifuged at $2000 \mathrm{rpm}$ for 3 minutes, and then analyzed for drug content spectrophotometrially (Shimadzu UV-1800, Japan)) at $272 \mathrm{~nm}$, and the concentration of soluble drug was calculated [10].

$$
\text { Entrapment efficiency }=\frac{\begin{array}{l}
\text { Weight of drug added during formulation } \\
\text {-weight of drug recovered from microspheres }
\end{array}}{\text { Weight of drug added during formulation }}
$$

\section{Swelling index}

Swelling index is determined by measuring the extent of swelling of microspheres in phosphate buffer of $\mathrm{pH}$ 6.8. To ensure the complete equilibrium, exactly weighed $100 \mathrm{mg}$ of microspheres were allowed to swell in buffer for $24 \mathrm{hrs}$. The swelling index is calculated using the following formula [10]:

$$
\alpha=\frac{\mathrm{W}_{2}-\mathrm{W}_{1}}{\mathrm{~W}_{1}}
$$

Where, $\alpha$ is swelling index, $\mathrm{W}_{1}$ is the weight of microspheres before swelling, and $\mathrm{W}_{2}$ is the weight of microspheres after swelling.

\section{Table 1: Composition of the formulations}

\begin{tabular}{llllllll}
\hline \multirow{2}{*}{ Formulation ingredients } & \multicolumn{7}{l}{ Formulation code } \\
\cline { 2 - 8 } & F1 & F2 & F3 & F4 & F5 & F6 & F7 \\
\hline Drug: Polymer & $1: 1$ & $1: 1.5$ & $1: 2$ & $1: 2.5$ & $1: 1$ & $1: 1.5$ & $1: 2$ \\
Venlafaxine HCL (mg) & 400 & 400 & 400 & 400 & 400 & 400 & 400 \\
Chitosan (mg) & 400 & 500 & 600 & 800 & 400 & 500 & 600 \\
Aq. Glacial acetic acid (\%) & 4 & 4 & 4 & 4 & 4 & 4 & 4 \\
Glutaraldehyde (ml) & 1.0 & 1.0 & 1.0 & 1.0 & 2.0 & 2.0 & 2.0 \\
Ethanol (ml) & 10 & 10 & 10 & 10 & 10 & 10 & 10 \\
Span 80 (ml) & 2 & 2 & 2 & 2 & 2 & 2 & 2 \\
Acetone & q.s & q.s & q.s & q.s & q.s & q.s & q.s \\
Formulation variables & & & & & & & \\
$\quad$ Crosslinking time (hr) & 1 & 1.5 & 2 & 1 & 1.5 & 2 & 2.5 \\
$\quad$ Speed & 900 & 900 & 900 & 1200 & 1200 & 1200 & 1500 \\
\hline
\end{tabular}

VENH: Venlafaxine hydrochloride, HCL: Hydrochloride

\section{Scanning electron microscopy (SEM) of microspheres}

The shape and surface characteristics of the microspheres were observed by SEM. The microsphere sample was thinly sprinkled onto a metal stub and vacuum coated with thin layer of gold in an argon atmosphere. The SEM photomicrographs of the coated particles were obtained at 15kv using a ZEISS, Germany, SEM [11].

\section{In-vitro washes off test}

The mucoadhesive property of the microspheres was evaluated by in-vitro adhesion testing method known as wash off method. A piece of nasal mucosa of $1 \times 1 \mathrm{~cm}$ was tied onto a glass slide using a thread. A weighed amount of microspheres was placed onto the wet rinsed tissue specimen, and the prepared slide was hung onto one of the grooves of a USP tablet disintegrating test apparatus. The disintegrating test apparatus was operated, wherein the tissue specimen was given up and down movements regularly in the beaker of the disintegrating apparatus, which contained the phosphate buffer of $\mathrm{pH}$ 6.4. After $1 \mathrm{hr}$ perfusate was analyzed for drug content. The adhered microspheres amount was estimated from the difference between the applied microspheres and the flowed microspheres amount $[8,12]$.

$\%$ Mucoadhesion $=\frac{\text { Weight of sample-weight of detached sample }}{\text { Weight of sample }} \times 100$

\section{In-vitro release studies}

The in-vitro release of venlafaxine microspheres was done with phosphate buffer $\mathrm{pH}$ of 6.4 for $8 \mathrm{hrs}$ by using dissolution apparatus USP I Basket type at a temperature of $37.0 \pm 0.5^{\circ} \mathrm{C}$. Microsphere equivalent to $10 \mathrm{mg}$ of drug was taken and it was inserted in the basket wrapping it with muslin cloth $\left(900 \mathrm{ml}\right.$ phosphate buffer $\mathrm{pH} 6.4$, at $37 \pm 2^{\circ} \mathrm{C}$ and was adjusted to $100 \mathrm{rpm}$ ). The sample was taken for every half an hour for $8 \mathrm{hrs}$. To maintain the sink condition, the samples withdrawn were replaced with an equal volume of dissolution medium at different time intervals. After suitable dilution, samples were analyzed at ultravioletvisible spectrophotometer at $272 \mathrm{~nm}$ [12]

\section{Formulation of the mucoadhesive microsphere-loaded nasal gel} The nasal gels with varying concentrations of Carbopol 934P were prepared by dispersing required quantity of Carbopol in required quantity of distilled water with continuous stirring and kept overnight for complete hydration. Further appropriate quantities of benzalkoniumchloride were added to previous polymeric mixture. Mucoadhesive microsphere of venlafaxine was added to the above polymeric mixture with constant stirring. Final $\mathrm{pH}$ of the preparation was adjusted to 4.5 with $0.5 \mathrm{M}$ sodium hydroxide solution. The gel was then further modified by the addition of varying proportion of HPMC K4M [13]. The composition of all the formulation is given in Table 2.

\section{Characterization of mucoadhesive microsphere gel}

Study of the physical properties

Determination of $\mathrm{pH}$

Determination of $\mathrm{pH}$ is done by using Systronic digital $\mathrm{pH}$ meter 335. $\mathrm{pH}$ meter was calibrated before use by using standard buffer solution.

\section{Viscosity}

The viscosity of the formulated gel is determined by DV-E Brookfield viscometer using spindle no 64

\section{Gel strength determination}

About $50 \mathrm{~g}$ of microspheres-loaded gel was taken in a beaker and a weight of $5 \mathrm{~g}$ was allowed to sink $5 \mathrm{~cm}$ down into the gel. The gel strength, which means the viscosity of the gel, was determined by the time (seconds) taken to touch the bottom $[14,15]$.

Mucoadhesive strength

It is determined by using Texture Analyser (TA. XT EXPRESS, Stable 
Micro Systems, UK, Godalming, Surrey). The mucoadhesive strength of the formulations was evaluated by measuring the force required to detach the formulation from a goat nasal mucosa [16].

\section{In vitro permeation study}

Evaluation of in vitro release studies of venlafaxine-loaded microsphere in Carbopol gel was carried out at $37^{\circ} \mathrm{C}$ using phosphate buffer $(\mathrm{pH}$ 6.4) as the release medium. A glass tube of $10 \mathrm{~mm}$ diameter and $100 \mathrm{~mm}$ height was taken. One end of the tube was closed using cellophane membrane with the help of adhesive tape while the other end was kept open and used as drug reservoir compartment. Gel $(1 \mathrm{~g})$ containing venlafaxine microsphere was accurately weighed and transferred to the glass tube in a vertical position through the open end. The gel was gently pushed down to the surface of the membrane. Phosphate buffer ( $2 \mathrm{ml}, \mathrm{pH} 6.4)$ was added to the reservoir compartment to wet the gel. The glass tube was placed in a beaker containing $100 \mathrm{ml}$ of phosphate buffer $(\mathrm{pH}$ 6.4). The receiving compartment was magnetically stirred $\left(100 \mathrm{rpm}\right.$, Remi, India) at $37^{\circ} \mathrm{C}$. Samples $(1 \mathrm{ml})$ were withdrawn from the receiving compartment at regular intervals, and the amount of venlafaxine released from the gel was determined using a spectrophotometer at $272 \mathrm{~nm}$. After each withdrawal of sample, equal quantity of citrate phosphate buffer was added to the receiving compartment to maintain the sink condition [17].

Permeability coefficient (P) was calculated from the slope of graph of percentage of drug transported v/s time, and equations are shown as follows [15].

\section{$\mathrm{P}=$ slope $^{*} \mathrm{Vd} / \mathrm{S}$}

Where, $\mathrm{Vd}=$ volume of donor solution, $\mathrm{S}=$ surface area of the cellophane membrane.

Flux $(J)=P * C D$

Where, $\mathrm{CD}$ is concentration of donor solution.

\section{Short-term stability studies}

Samples were stored in a plastic container for 2 months at $4{ }^{\circ} \mathrm{C}$ in freeze and at room temperature. After 30 and 60 days, samples were visually observed for any sedimentation and subjected for $\mathrm{pH}$, viscosity, and in vitro release studies were carried out at every 1 month interval $[18,19]$.

\section{RESULTS AND DISCUSSION}

FT-IR incompatibility study of drug and excipients

FT-IR spectroscopy was carried out to test the compatibility of venlafaxine with chitosan in the formulation shown in Fig 1. FT-IR spectrum of venlafaxine showed the presence of characteristics band at $3317.87,1533.42,1238.22,1036.92,960.77,823.21 \mathrm{~cm}^{-1}$ due to $\mathrm{N}-\mathrm{H}$ stretching, $\mathrm{N}-\mathrm{H}$ bending, $\mathrm{O}-\mathrm{H}$ bending, $\mathrm{C}-\mathrm{O}$ stretching, C-C stretching, and $\mathrm{C}-\mathrm{H}$ stretching. All these characteristics band also retained in 1:1 physical mixture of venlafaxine-chitosan are shown in Fig. 1. The results clearly revealed the compatibility of drug with the excipients used in the formulation. It shows that there was no significant change in the chemical integrity of the drug.

Table 2: Formulation of microsphere-loaded nasal gel

\begin{tabular}{|c|c|c|c|c|}
\hline Formulation code & Carbopol 934P (\%w/v) & HPMC K4M (\%w/v) & Benzalkonium chloride ( $\% w / v)$ & Distilled water \\
\hline GF1 & 0.1 & - & 0.02 & q.s \\
\hline GF2 & 0.2 & - & 0.02 & q.s \\
\hline GF3 & 0.5 & 0.25 & 0.02 & q.s \\
\hline GF4 & 0.5 & 0.5 & 0.02 & q.s \\
\hline GF5 & 0.5 & 0.75 & 0.02 & q.s \\
\hline GF6 & 0.5 & 1.0 & 0.02 & q.s \\
\hline
\end{tabular}

HPMC: Hydroxypropyl methylcellulose

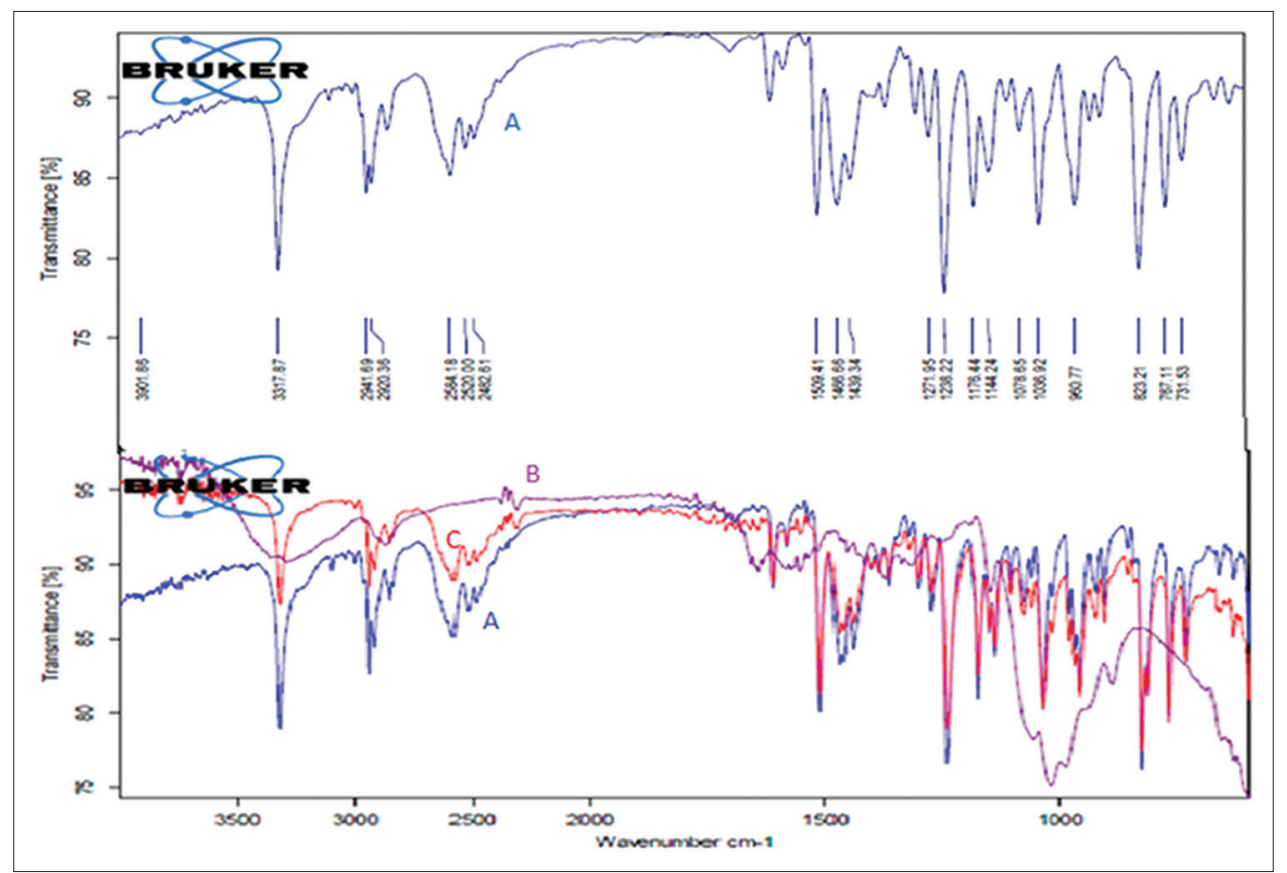

Fig. 1: Fourier transform-infrared spectroscopy spectra of venlafaxine hydrochloride (a), Chitosan (b), and 1:1 physical mixture of venlafaxine hydrochloride and chitosan (c) 


\section{Evaluation of the chitosan microspheres}

\section{Surface morphology and particle size analysis}

The particle size of all the formulations was found to be in the range of 10-50 $\mu \mathrm{m}$. Formulation F4 was selected as the optimized formulation as the particles' size was between 10 and $20 \mu \mathrm{m}$, and the surface was found to be smooth and spherical. Sapna et al., (2011) prepared microspheres of midazolam by the emulsification cross-linking method using glutaraldehyde as cross-linking agent. The microspheres obtained under these conditions were found to be spherical and without aggregation, and median size ranged from 7-18 $\mu \mathrm{m}$ and are therefore suitable for nose-to-brain administration [9].

\section{Encapsulation efficiency}

The encapsulation efficiency ranged from $41.6 \%$ to $78.40 \%$. The encapsulation efficiency increased as the concentration of polymer (encapsulating material) was increased. These results are similar to the findings of Dandagi et al., (2014) where encapsulation efficiency ranged from $54.7 \%$ to $85.86 \%$ of the carbamazepine-loaded chitosan microspheres for the preparation of thermosensitive nasal gel [16]. The results of encapsulation efficiency are tabulated in Table 5.

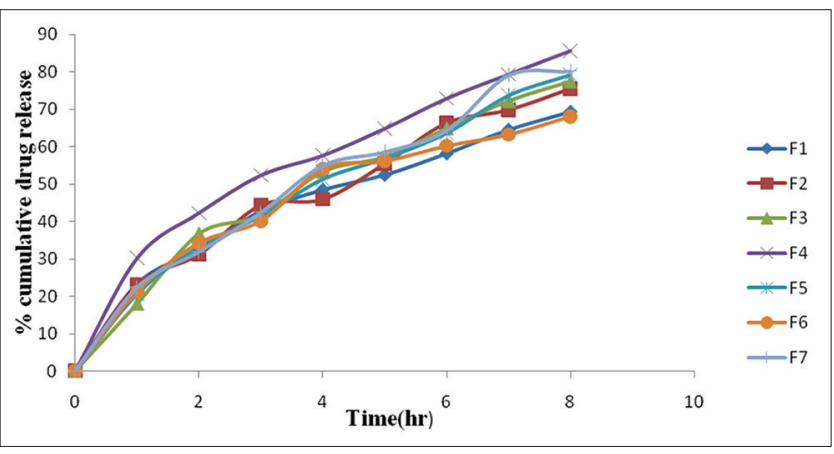

Fig. 2: Comparative in vitro dissolution profile of microspheres (F1-F7)

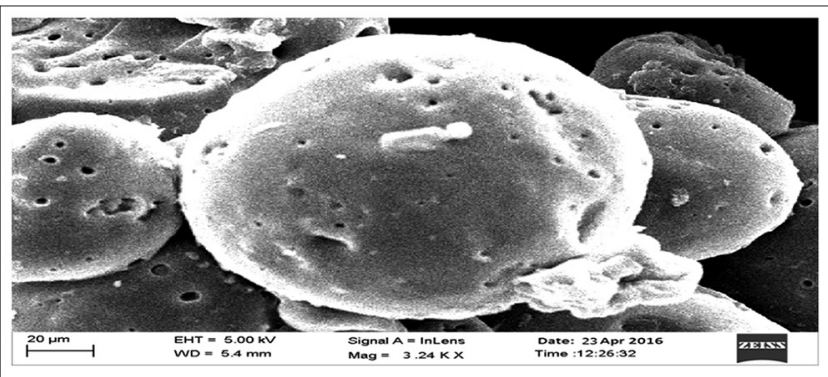

Fig. 3: Scanning electron microscopy of venlafaxine hydrochloride-loaded chitosan microspheres

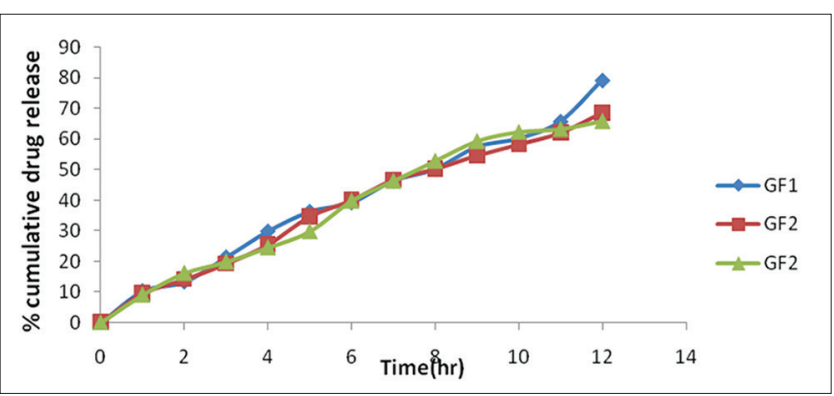

Fig. 4: In vitro drug release of formulations GF4, GF5, and GF6

\section{In-vitro drug release study}

In vitro release profile of VNFH -loaded microspheres in phosphate buffer with pH of 6.4 is shown in Fig. 2. Here, sustained release of drug was observed from the formulation in phosphate buffer $(\mathrm{pH}$ 6.4) for a duration of $8 \mathrm{hrs}$. About 58.09-72.89\% of drug release was achieved in less than 6 hrs from the chitosan microspheres. Gavini et al., (2006) suggested that chitosan, a polymeric material, is known for its properties of dissolution rate enhancer of drugs poorly soluble in water [10]. The improvement of the dissolution rate of the drug from the microspheres can be also due to their small size and the cross-linking of polymer and drug that lead to the uniform dispersion of the drug into the polymeric network. The cumulative percentage drug release from formulation F1, F2, F3, F4, F5, F6, and F7 was found to be $69.26 \%, 75.41 \%, 77.45 \%$, $85.67 \%, 79.15 \%, 68.17 \%$, and $80.15 \%$, respectively.

\section{Scanning electron microscopy}

The microspheres prepared by solvent evaporation method have good spherical shape with smooth surface in its morphology and the particles were distributed uniformly without forming any clumps.The SEM image of optimized formulation(F4) is shown in Fig 3.

\section{Characterization of gel-containing microspheres}

pH of gels

$\mathrm{pH}$ of all the formulations was found to be between 4.5 and 6.19. The variation in $\mathrm{pH}$ was attributed to the concentration of Carbopol and HPMCK4M in the formulation. Jose et al., (2013) suggested the pH of the nasal gel formulations to be 5.23-6.08 [13].

\section{Viscosity}

Viscosity of the gels was determined using DV-E Brookfield viscometer using spindle no 64 .

The viscosity was found to be $1056 \mathrm{cps}, 1130 \mathrm{cps}$, and $1271 \mathrm{cps}$ of GF 4 , GF5, and GF6, respectively. The increase in viscosity of the formulations was directly proportional to the polymer concentration. Khalandar et al., (2011) studied the viscosity of the nasal gel of sumatriptan and they found the viscosities of 1047, 1186, and 1242 are functional for nasal application [19].

\section{In vitro diffusion study}

The permeation data obtained for formulations GF4, GF5, and GF6 are shown in Table 5. The overall cumulative percentage drug permeated for GF4, GF5, and GF6 was found to be $79.28 \%, 68.72 \%$, and $65.76 \%$, respectively. The amount of drug permeated across the nasal mucosa at the end of $12 \mathrm{hrs}$ was maximum, i.e., $79.28 \%$ for F1. The lower drug release of formulations GF5 and GF6 as compared to GF4 may be attributed to the higher polymer concentration in the former. Sharma et al., (2014) suggested about $73.98-86.46 \%$ of drug release was achieved in less than $8 \mathrm{hrs}$ from chitosan microspheres. The lower drug release of formulations may be attributed to the high polymer concentration in the former. With an increase in the polymer concentration, the micelles formed are closely packed on gellation, thus resisting the drug release to the external environment [16].

\section{Stability studies}

A stability study of the optimized formulation was done for appearance, $\mathrm{pH}$, and viscosity for up to 60 days at a time interval of 30 days. The formulation did not show much variation in any of the parameters. The results obtained were tabulated in Table 6. From these results, it was concluded that formulation GF1 was stable throughout the period.

\section{Gel strength study}

The gel strength,which means the viscosity of the gels was determined by the time(seconds), the apparatus took to sink $5 \mathrm{~cm}$ down through the prepared gel.The results were tabulated in Table:4. Majithiya RJ et al.(2006)suggested the gel strength values between 25 and $50 \mathrm{~s}$ are 
Table 3: Evaluation parameters of the microspheres

\begin{tabular}{|c|c|c|c|c|c|c|}
\hline Formulation code & $\%$ yield & $\begin{array}{l}\text { Drug entrapment } \\
\text { efficiency }\end{array}$ & Average particle size & $\%$ swelling index & $\%$ mucoadhesion after $1 \mathrm{hr}$ & In vitro drug release \\
\hline F1 & 43.75 & 41.6 & 12.36 & 66.5 & 62.24 & 69.26 \\
\hline F2 & 44.45 & 47.91 & 15.43 & 67.9 & 76.92 & 75.41 \\
\hline F3 & 65 & 67.45 & 19.25 & 74.3 & 80.12 & 77.45 \\
\hline F4 & 79.16 & 78.40 & 15.56 & 102.6 & 88.18 & 85.67 \\
\hline F5 & 47 & 59.16 & 20.78 & 167 & 55.56 & 79.15 \\
\hline F6 & 48.88 & 51.37 & 24.67 & 93.7 & 52.34 & 68.17 \\
\hline F7 & 54.5 & 67.5 & 13.89 & 119.6 & 58.67 & 80.15 \\
\hline
\end{tabular}

Table 4: Evaluation parameters of the microsphere-loaded gel

\begin{tabular}{|c|c|c|c|c|c|}
\hline \multirow[t]{2}{*}{ Formulation code } & \multirow[t]{2}{*}{$\mathbf{p H}$} & \multirow[t]{2}{*}{ Gel strength (sec) } & \multicolumn{2}{|c|}{ Viscosity (cps) } & \multirow[t]{2}{*}{ Mucoadhesive force (dyne $/ \mathrm{cm}^{2}$ ) } \\
\hline & & & Soln & gel & \\
\hline GF1 & 5.2 & 14.56 & 196 & 920 & 14.19 \\
\hline GF3 & 4.97 & 25.60 & 260 & 1176 & 23.55 \\
\hline GF4 & 4.51 & 31.87 & 335 & 1056 & 55.38 \\
\hline GF5 & 6.01 & 38.26 & 286 & 1130 & 37.59 \\
\hline GF6 & 5.7 & 40.51 & 387 & 1272 & 60.26 \\
\hline
\end{tabular}

Table 5: Result of permeation study

\begin{tabular}{llll}
\hline $\begin{array}{l}\text { Formulation } \\
\text { code }\end{array}$ & $\begin{array}{l}\text { \% drug } \\
\text { release }\end{array}$ & $\left.\begin{array}{l}\text { Permeation coefficient } \\
\left(\mathbf{m g c m}^{\mathbf{2}} \mathbf{h r}\right.\end{array} \mathbf{- 1}\right)$ & Flux $\left(\mathbf{m g c m}^{\mathbf{2}} \mathbf{h r}^{-\mathbf{1}}\right.$ ) \\
\hline GF4 & 79.28 & 0.11872 & 1.1872 \\
GF5 & 68.72 & 0.11206 & 1.1206 \\
GF6 & 65.76 & 0.11426 & 1.1426 \\
\hline
\end{tabular}

Table 6: Stability study of the best formulation GF4

\begin{tabular}{lllllll}
\hline \multirow{2}{*}{$\begin{array}{l}\text { Evaluation } \\
\text { parameters }\end{array}$} & \multicolumn{3}{l}{ Optimized formulation GF4 } & \\
\cline { 2 - 4 } & Initial & $\mathbf{3 4}^{\circ} \mathbf{C}$ & & & Room temperature \\
\cline { 2 - 4 } \cline { 6 - 6 } & & $\mathbf{3 0}$ days & $\mathbf{6 0}$ days & & $\mathbf{3 0}$ days & $\mathbf{6 0}$ days \\
\hline $\mathrm{pH}$ & 4.51 & 4.50 & 4.48 & & 4.39 & 4.32 \\
Viscosity & 1056 & 1055 & 1053 & & 1050 & 1050 \\
\hline
\end{tabular}

considered sufficient, as gel strength of less than $25 \mathrm{~s}$ may not preserve its integrity and may erode rapidly while gels with strength greater than $50 \mathrm{~s}$ are too stiff and may cause discomfort.(21)

\section{CONCLUSION}

From the present study, it was concluded that mucoadhesive intranasal microsphere gel of drug VNFH can be prepared using emulsification cross-linking method. Controlled release mucoadhesive microspheres were successfully prepared employing emulsification cross-linking technique using polymer chitosan. Microspheres containing venlafaxine and chitosan in the ratio (1: 2.5 ), i.e., formulation F4 were found to be optimized based on various parameters such as particle shape and size, drug content, encapsulation efficiency, in vitro bioadhesiveness, and drug release. Gels were formulated with an optimized quantity of Carbopol 934P and HPMC K4M. In vitro diffusion studies on the gel suggested sustained drug release and that concentration of polymer in gel played a significant role in drug release. Gel formulation GF4 found to be stable in the short-term stability study.

\section{ACKNOWLEDGMENTS}

First, I would like to thank my Principal Dr. Suvakanta Dash for giving me an opportunity to do the research work. Also, I would pay my sincere gratitude to my guide, Assistant professor, Mr. Bhupen Kalita for his guidance, supervision, and helping me throughout the research work. The authors are thankful to Merck specialist Pvt. Ltd., for providing VENH, and Merck Company for providing necessary chemicals required for the research work. The authors also pay their warm thanks to Girijananda Chowdhury Institute of Pharmaceutical Science for providing the necessary facilities to carry out the research work successfully.

\section{REFERENCES}

1. Nasare L, Niranjane K, Nagdevte A, SumedhMohril, Nasal drug delivery system: An emerging approach for brain targeting. World J Pharm Sci 2014;3(4):539-53.

2. Bhosale AV, Chaudhari PD. A review on nose-to-brain drug delivery. Int J Pharm Sci Rev Res 2013;2(1):516-25.

3. Dhakar RC. Non-invasive systemic drug delivery via nasal route: A review. AJPSP 2011;2(1):114-44.

4. Dhakar RC, Maurya SD, Tilak VK, Gupta AK. A review on factors affecting the design of nasal drug delivery system. Int J Drug Deliv 2011;3:194-208.4.

5. Chaudhari A, Jadhav KR, Kadam VJ. An overview: Microspheres as a nasal drug delivery system. Approach for brain targeting. WJPR. Int J Pharm Sci Rev Res 2014;3(4):539-53.

6. Illum L. Nasal drug delivery - possibilities, problems and solutions. J Control Release 2003;87(1-3):187-98.

7. Gowri R, Narayanan N, Maheswaran A, Janarthanan S, Paulra S, Lavanya P. Mucoadhesive microspheres - A virtuous bioavailability embellishing tool. Int J Pharm 2013;3(4):763-73.

8. Vasir JK, Tambwekar K, Garg S. Bioadhesive microspheres as a controlled drug delivery system. Int J Pharm 2003;255(1-2):13-32.

9. Desai S, Vidyasagar G, Shah V, Desai D. Preparation and in-vitro characterization of mucoadhesive microspheres of Midazolam: Nose to brain administration. Asian J Pharm Clin Res 2011;4(1):100-2.

10. Gavini E, Hegge AB, Rassu G, Sanna V, Testa C, Pirisino G, et al. Nasal administration of carbamazepine using chitosan microspheres: In vitro/ in vivo studies. Int J Pharm 2006;307(1):9-15.

11. Doddayya H, Srishailgouda SP, Reddy BT, Kumar P, Rajagopal HU, Shree MV. Formulation and evaluation of brain-targeted nasal selegiline hydrochloride microspheres. Int J Pharm Biomed Res 2014;5(3):61-8.

12. Rathananand M, Kumar DS, Shirwaikar A, Kumar R, Sampath DK, Prasad RS. Preparation of mucoadhesive microspheres for nasal delivery by spray drying. Indian J Pharm Sci 2007;69(5):651-7.

13. Jose S, Ansa CR, Cinu TA, Chacko AJ, Aleykutty NA, Ferreira SV, et al. Thermosensitive gels containing Lorazepam microspheres for brain targeting. Int J Pharm 2013;441:516-26.

14. Gaikwad M, Sahasrabuddhe S, Puranik P. Development and evaluation of carbamazepine loaded transfersomal in-situ gel for nose to brain delivery. Indo Am J Pharm Res 2015;5(05):47-53.

15. Bhandwalkar MJ, Avachat AM. Thermoreversible nasal in situ 
gel of venlafaxine hydrochloride: Formulation, characterization and pharmacodynamic evaluation. AAPS PharmSciTech 2013;14(1):101-10.

16. Dandagi PM, Sharma R, Gadad AP, Mastiholimath V. Thermo sensitive gels containing carbamazepine microspheres for intranasal targeting. WJPR 2014;3(9):716-30.

17. Hardenia SS, Jain A, Patel A, Kaushal A. Formulation and evaluation of mucoadhesive microspheres of ciprofloxacin. JAPER 2011;1(4):214-4.

18. Senthil A, Kumar RB, Vinod BD, Bharat BL, Battu BL. Formulation and evaluation of mucoadhesive microspheres of venlafexine $\mathrm{HCl}$. Int
Res J Pharm 2011;2(4):194-9.

19. Dada Khalandar KS, Yajaman S, Jayaveera KN. Chitosan based nasa microspheres of sumatriptan: Formulation and in-vitro evaluation. Res J Pharm Biol Chem Sci 2011;2(3):489-98.

20. Deshpande T, Masareddy R, Bolmal U. Development of mucoadhesive microspheres for nasal delivery of sumatriptan. Int J Pharm Sci Rev Res 2011;7(2):193-7.

21. Majithiya RJ, Ghosh PK, Umrethia ML, Murthy RS. Thermoreversiblemucoadhesive gel for nasal delivery of sumatriptan. AAPS PharmSciTech 2006;7(3):67. 